\title{
Flipped classroom as a methodology to acquire knowledge and skills in an integrated manner in basic subjects in Medicine.
}

\author{
C. Azpeleta*, B. Gal", F. Suárez*, C. Sánchez-Camacho*\# \\ Dpto. Ciencias Biomédicas Básicas, Facultad de Ciencias Biomédicas y de la Salud \\ Universidad Europea de Madrid \\ C/ Tajo s/n, Villaviciosa de Odón, 28670 Madrid \\ \#e-mail: cristina.sanchez-camacho@uem.es
}

\begin{abstract}
The present study analyses the inclusion of the flipped classroom methodology in the Physiology I (Cellular Physiology) course of the Degree in Medicine. This methodology was carried out as an integrated activity including the concepts acquired in some lessons of the course, all of them related to the different types of muscle: skeletal, cardiac and smooth. With this aim, after two months explaining the theoretical concepts about this topic, the Professors laid out an activity focused on the review of these concepts by searching the common and differential characteristics of each type of muscle. A survey designed by teachers was used to analyze the assessment of the activity by the students and the suggestion of possible improvements. The results obtained show a very positive global evaluation (87\% of the students), with $98-99 \%$ satisfied or highly satisfied with the objectives of the activity, and $89-98 \%$ who assessed positively this methodology. Thus, our results support the use of the flipped classroom methodology in the teaching process, as a useful tool for the improvement of students' learning, and encourage us to include more activities following this methodology in academic years to come.
\end{abstract}

Keywords: Flipped classroom; integration; physiology; satisfaction.

\section{Introduction}

In recent years, Spanish Universities have been working to implement new teaching methodologies in the context of the European Higher Education Area (http://www.magna-charta.org/resources/files/BOLOGNA_DECLARATION.pdf).

New technological advances are now being applied to improve teaching and learning. However, an appropriate balance between the acquisition of knowledge and the acquisition of skills and abilities is a major issue. On the one hand, it has been shown that traditional lectures are effective in transmitting information and guiding student's learning (Gage and Berliner, 1998; Hudson and Buckley, 2004). On the other hand, numerous studies have reported that the use of different methodologies such as problem-based learning, internships, and other participatory approaches enhance the integration of knowledge acquired during lectures (Hudson and Buckley, 2004; Walters, 1999; Waters et al., 2005). However, developing teaching methodologies aimed at maximizing acquisition of knowledge and skills still remains a real challenge.

One of the most powerful techniques in higher education is the flipped classroom (http://flippedclassroom3.weebly.com/iquestqueacute-es-flipped-classroom.html).

This learning methodology implies "doing the class in reverse order". Traditionally, students learn from lectures first to then deepen their understanding or apply concepts through independent work. Applying the flipped classroom method is "reversing the learning process". By using different technological and communication tools, students have access to content, prior to and away from the classroom. These resources enable students to establish a first contact with the contents to learn. Back in the classroom, students have to use the acquired knowledge by doing different tasks (asking 
questions, discussing, developing resources, practical work, etc.) under the facilitation of the Professor.

Physiology I (Cellular Physiology for the remainder) is taught in the first year of the Degree in Medicine. It has a basic and transversal character, and its content is essential for learning through later stages. A team of Professors on Physiology of the Universidad Europea de Madrid (UEM) have recently worked to integrate concepts explained in different physiology contents, with a dual purpose: first, that the students do not consider each system isolated, but the organism as a whole, and second, to understand that the specific characteristics of every cell, tissue and organ is what determines its function. This integrated approach provides a deeper understanding and a more holistic view of human physiology when compared with classical lecturebased teaching (Bain, 2007; Gal et al., 2013). This approach is especially suitable for promoting important skills such as autonomous learning or critical thinking. The flipped classroom represents an example of a possible methodology to acquire knowledge and skills in an integrated manner.

Consequently, the major goals of this work are:

- To increase the proportion of advanced learning methodologies versus traditional lecture-based teaching in the syllabus of Cellular Physiology for the first year of the Degree in Medicine. In particular, we will focus on using the flipped classroom as an alternative methodology.

- To encourage integrated learning.

- To promote the following skills: autonomous learning and critical thinking.

- To improve and quantify our own perception of student's learning through this activity.

\section{Methods}

As Professors in Physiology of the first year in Medicine, we planned an activity for our students to integrate distinct concepts related to muscle tissue. This activity was developed during the 2013-2014 academic year, by introducing a new methodology of teaching and learning known as flipped classroom, as described below.

\section{Activity plan}

For two months, the Professor taught the content of the activity in the classroom by using lectures, which included five units in the syllabus of Cellular Physiology. These lessons comprise the study of the three types of the muscle tissue: skeletal, cardiac and smooth. During this period, we went into detail about distinct aspects of muscle physiology. After finishing this part of the subject, we proposed to our students that they reviewed these contents looking for shared and particular characteristics of each type of muscle, including biochemical, histological or physiological features. These characteristics should be presented in a table undertaken as homework. After doing this activity, the students valued different aspects of it by means of a survey designed by the Professors of Physiology.

The activity, initially planned as non-graded, was undertaken in a total number of 9 distinct groups of the first year in Medicine and the survey was valued for a total number of 130 students. We would like to note that apart from using this new methodology, the flipped classroom, we also integrated the contents of distinct lessons in the activity, so that the students could compare the characteristics of the three types 
of muscles. We dedicated 60 to 90 minutes on average for doing this activity in the classroom.

\section{Survey}

We created a satisfaction survey for the students in which we included items to evaluate the objectives of the practice session (level of satisfaction and level of learning) and the methodology used (structure, organization and length of the activity), as well as a question to assess the global valuation of the activity. Also, we added a section in the survey for the students to include their comments and suggestions on the activity (Fig. 1).

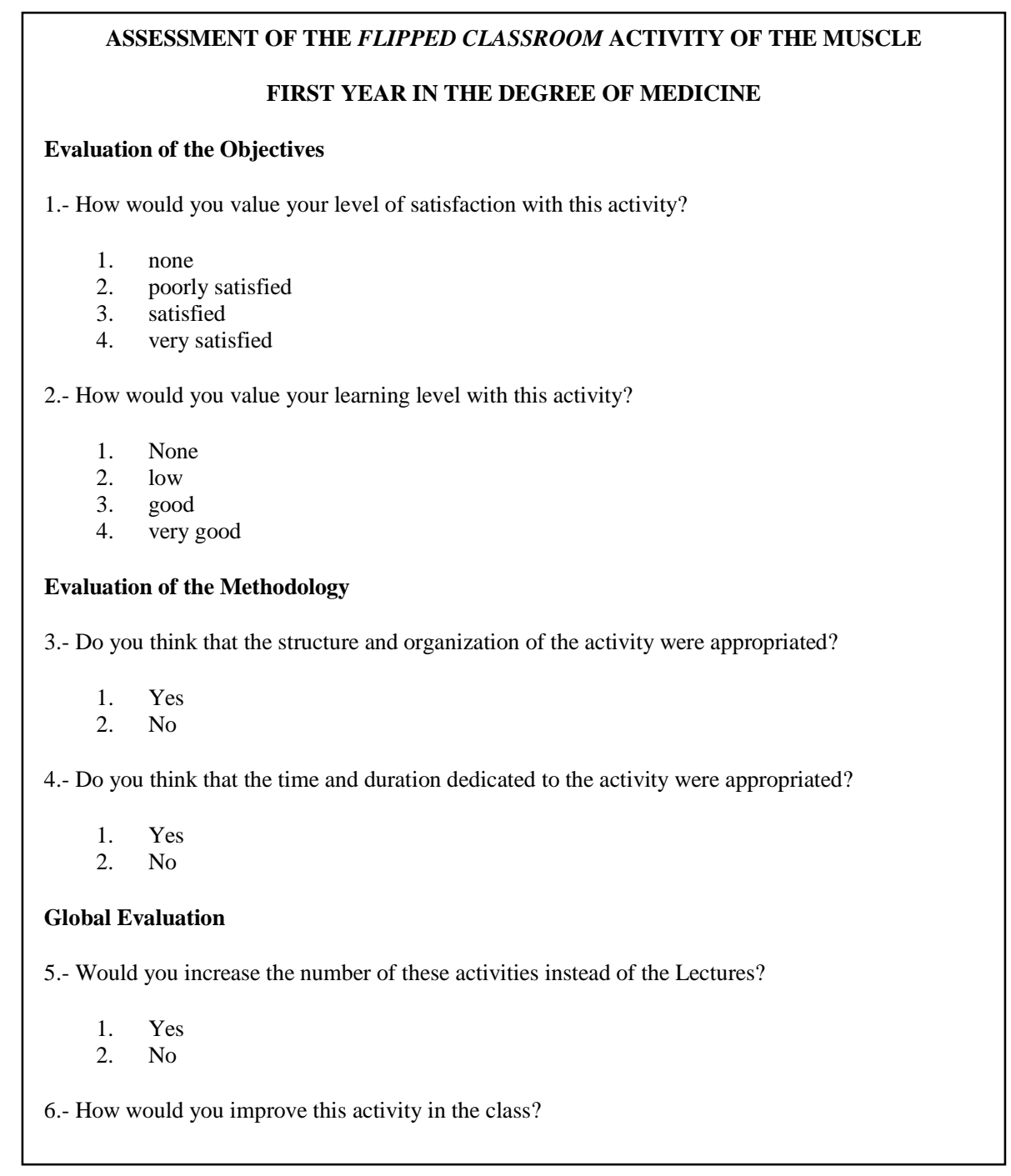

Figure 1. Survey taken by the students to value the activity. 


\section{Results and Discussion}

In this work we implemented a flipped classroom methodology on Cellular Physiology for medical students. As a result, we empowered the students to be part of the class, collaborating with others (peer instruction; Lasry et al., 2008; Manzur, 2009). To achieve this purpose we chose the muscle physiology because this physiological system is very suitable to establish similarities and differences amongst muscle types. Nevertheless, there are several other areas of our subject where this methodology could, potentially, be employed as well: transport across cell membranes, neurochemistry and immunology, to name just a few of them.

The authors of this article evaluated this methodology in a very positive way. In addition, students' perception was in the same direction as ours. In general, our results demonstrated a very positive assessment of the activity by most of the students in all the sampled groups. Students evaluated positively all the items included in this survey: satisfaction, learning, structure and organization, duration and global outcome.

For the evaluation of the objectives, two items were analyzed: level of satisfaction and level of learning. Regarding to the first, most of the students (54\% satisfied; $45 \%$ very satisfied) were quite satisfied with the activity and the outlined objectives (Fig. 2). This evaluation was correlated with the level of learning, in which $98 \%$ of the students considered it good (58\%) or very good (40\%) (Fig. 3).

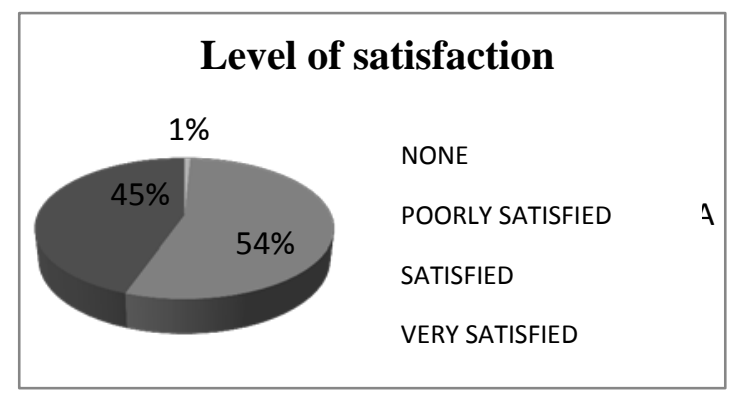

Figure 2. Assessment of the level of satisfaction with the activity.

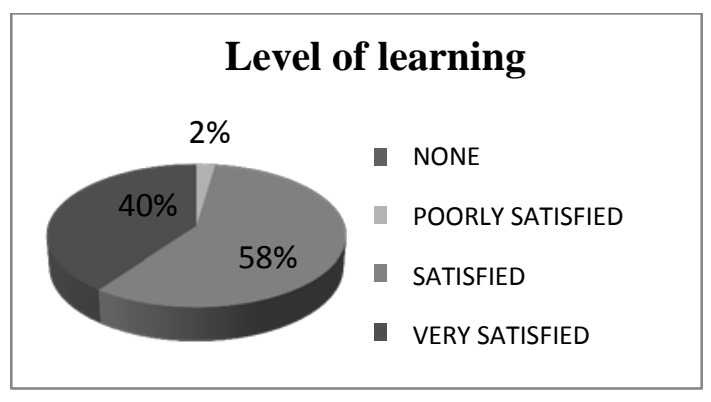

Figure 3. Assessment of the level of learning with the activity.

Another parameter analyzed was the methodology, including the evaluation of structure, organization and duration of the activity. Almost all the students (98\%) considered that the structure and organization were appropriate (Fig. 4), whereas the remaining $2 \%$ stated that the time allotted to accomplish the activity was insufficient, probably due to the lack of time in previous classes for explaining the theoretical concepts of the lesson. Regarding the duration of the activity, $89 \%$ of the students considered it adequate, while the remaining $11 \%$ considered that more time should be allotted (Fig. 5). This latter case includes the mentioned group in which the duration of the activity was shorter. 


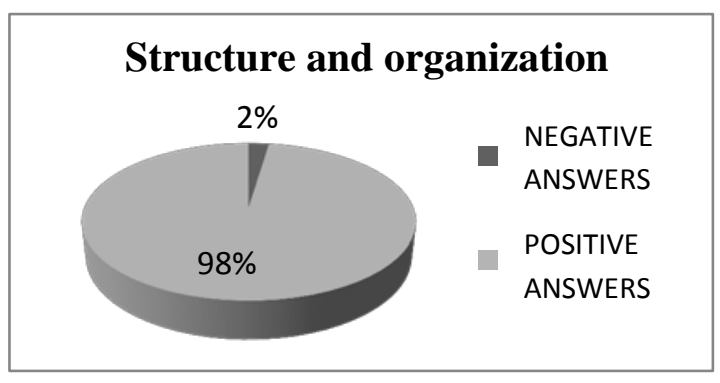

Figure 4. Assessment of the structure and organization of the activity.

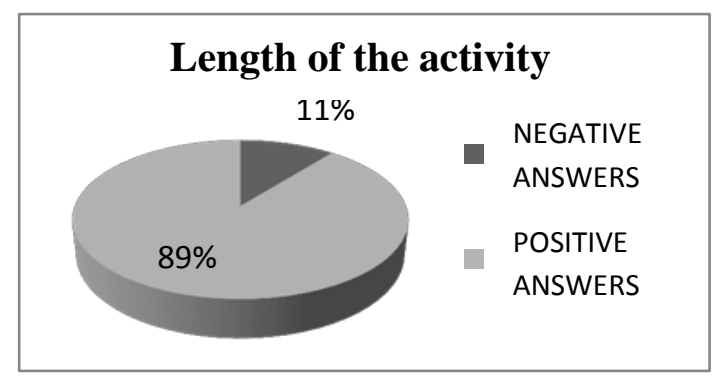

Figura 5. Assessment of the duration and time allotted for the activity.

With respect to the global evaluation, $87 \%$ of the students would increase the frequency of this kind of activities instead of master classes, while the remaining $13 \%$ would not (Fig. 6).

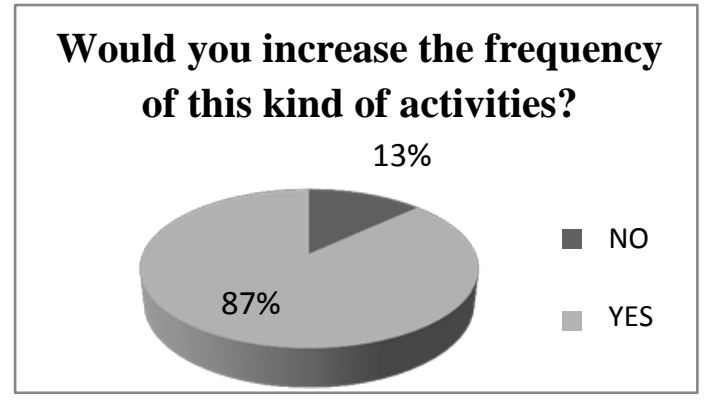

Figure 6. Global evaluation of the activity.
Finally, although the response was very positive, $60 \%$ of the surveyed students had some comments regarding the improvement of this activity. These suggestions were grouped in four categories:

- Encouraging student participation.

- Increase in the frequency of this type of activities in the course.

- Increase in the time allotted for the activity.

- Other: grading the activity, the use of other methodologies such as clinical cases, etc.

In general, comments about the activity were quite good and only $7.7 \%$ of the students considered that the activity could not be improved. It was a surprise the fact that $14 \%$ of the students would like their peers to be more proactive. This is something we had already observed in previous classes. As a way to improve proactivity, we are determined to increase the weight given to this activity on the final mark, as well as to include peer-review evaluation.

As cited by Manzur (http://harvardmagazine.com/2012/03/twilight-of-the-lecture) many students pay a huge amount of money not to work in class but for someone (the Professor) to work for them: in the master class. In our experience, we have seen that our students enjoyed these activities regardless of this. Moreover only $14 \%$ of the students pointed out improvements of the activity, suggesting repeating this activity in the future, but closer to exam preparation. For all the above mentioned, we consider that the flipped classroom is a very useful methodology to improve the learning and some skills of our students, such as autonomous learning and critical thinking, that can be used as a complement within the master classes and other activities in the classroom. Moreover, the use of this methodology could be transferred to basic subjects in Medicine as Biochemisty, Cell Biology, Genetics or Anatomy. 


\section{Conclusions}

- The flipped classroom methodology is a very useful tool for teaching Cellular Physiology in the first year of the Degree in Medicine, as it encourages integrated learning and promotes autonomous learning and critical reasoning in students.

- Students state to be highly satisfied with the inclusion of this activity as a complement to master classes and they demand of doing even more similar activities to encourage their learning.

- The Professors of Physiology are considering increasing the frequency of this type of activities in the syllabus of the course in the future, including improvements based on the suggestions of the students.

- The Professors of Physiology consider that this activity should be evaluated so that the students could receive feed-back of their knowledge.

\section{References}

Bain, K. (2007). Lo que hacen los mejores profesores universitarios. Valencia: Editorial Universidad de Valencia.

Gage, N., Berliner, D. (1998). Educational Psychology. Boston, MA: Hoghton Mifflin.

Gal, B., Fernández-Santander, A., Palau, L., Sánchez, A. (2013). Integrar asignaturas básicas en primero de Medicina: análisis cuantitativo y cualitativo de una experiencia piloto. Educación Médica, 16(4), 225-231.

Hudson, J.N., Buckley, P. (2004). An evaluation of case-based teaching: evidence for continuing benefit anda ralization of aims. Advances in Physiology Education, 28, $15-22$.

Lasry, N., Manzur, E., Watkins, J. (2008). Peer Instruction: From Harvard to Community Colleges. American Journal of Physics, 76, 1066-1069.

Manzur, E. (2009). Farewell, Lecture? Science, 323, 50-51.

Walters, M.R. (1999). Case-stimulated learning within endocrine physiology lectures: an approach applicable to other disciplines. Advances in Physiology Education, 276, 74-78.

Waters, J.R., Van Meter, P., Perrotti, W., Drogo, S., Cyr, R.J. (2005). Cat dissection vs. sculpting human structures in clay: an analysis of two approaches to undergraduate human anatomy laboratory education. Advances in Physiology Education, 29, 27-34. 